\title{
Los medios instruccionales, su desarrollo e importancia en la educación del siglo XXI
}

The instructional means, their development and importance in the education of the 21 st century

Os meios instrucionais, seu desenvolvimento e importância na educação do século XXI

\author{
BELKYS JULIANA GUZMÁN ${ }^{1}$ \\ SANTIAGO CASTRO ${ }^{2}$
}

\begin{abstract}
RESUMEN
En los procesos de enseñanza y aprendizaje en cualquier modalidad del sistema, sea presencial, mixta o a distancia, uno de los elementos primordiales son los medios y recursos instruccionales que ofrecen al educando la oportunidad de tener el conocimiento en forma variada, dinámica y accesible. Estos medios tienen la información y se usan para medir la misma con fines educativos por ello deben ser contextualizados, centrados en las características de los estudiantes. Este artículo es un estudio documental que radicó en la selección y compilación de información proveniente de documentos que permitieron reflexionar y compilar realidades teóricas y empíricas donde se indaga, e interpretan hallazgos, cuyo objetivo es desarrollar el estado del arte en relación con los medios instruccionales, un poco de historia, conceptos, clasificación, el diseño y producción de los mismos en diferentes formatos y su utilización en la educación del ciudadano que requiere el siglo XXI.
\end{abstract}

Palabras clave: Medios instruccionales; Tecnologías de Información y Comunicación (TIC); Tecnologías de Aprendizaje y Conocimiento (TAC).

\begin{abstract}
In the teaching and learning processes in any modality of the system, whether face-to-face, mixed or distance; one of the primary elements are the means and instructional resources that offer to the student the opportunity to have knowledge in a varied, dynamic and accessible way. These media have the information and are used to measure it for educational purposes so it must be contextualized, focusing on the characteristics of the students. This article is a documentary study that was based on the selection and compilation of information from documents that allowed us to reflect and compile theoretical and empirical realities where it is investigated, and interpret findings. The objective is to develop the state of the art in relation to the instructional means, a bit of history, concepts, classification, the design and production of them in different formats and their use in the education of the citizen that the 21 st century requires.
\end{abstract}


Keywords: Instructional means; Information and Communication Technologies (ICT); Learning and Knowledge Technologies (TAC).

\section{RESUMO}

Nos processos de ensino e aprendizagem em qualquer modalidade do sistema, seja presencial, mista ou a distância; um dos elementos principais são os meios e recursos instrucionais que oferecem ao aluno a oportunidade de ter conhecimento de maneira variada, dinâmica e acessível. Essas mídias possuem as informações e são usadas para medi-las para fins educacionais, de modo que devem ser contextualizadas, com foco nas características dos alunos. O objetivo é desenvolver o estado da arte em relação aos meios instrucionais, um pouco de história, conceitos, classificação, design e produção deles em diferentes formatos e seu uso na educação do cidadão que o século XXI exige.

Palavras-chave: Meios instrutivos; Tecnologias de Informação e Comunicação (TIC); Tecnologias de Aprendizagem e Conhecimento (TAC).

\section{INTRODUCCIÓN}

La Tecnología creada por y para el hombre ha permitido ver el mundo macro y microscópicamente. El humano ha creado todo tipo artefactos que han permitido romper las barreras espacio tiempo, comunicarse, interactuar con otros e interrelacionarse, nacer, crecer, estudiar, reproducirse o no, trabajar, ser líder y vivir, en conclusión, solucionar sus problemas. Se crea o no forma la cultura y también moldea nuestros valores. Es por ello que el sistema educativo no escapa de ese motor que ha impulsado e impulsa cambios que requieren respuesta entre ellos los medios.

Castro, Guzmán, \& Casado (2007) y Guzmán $(2005,2008,2013,2018)$ señalan que las características de las TIC promueven la interacción, el intercambio de roles entre los actores (docentes y estudiantes) de los procesos de enseñanza y aprendizaje, promueven cambios en las estrategias, los medios y recursos, propiciando la interactividad, la autorregulación y la motivación de los entes que consumen, producen y distribuyen información.

Para Lozano (2011), Montero (2014), Castañeda y Adell (2013), RM (2015) \& Cabero (2015) las TIC facilitan los procesos de transmisión e intercambio de información, en todos los ámbitos de la vida incluyendo el ámbito educativo, es por ello que como necesidad educativa surge el término TAC (Tecnologías del Aprendizaje y del Conocimiento), referido al uso de las TIC como herramienta formativa, incidiendo en la metodología y en la utilización de la tecnología dentro de las planificaciones educativas. Así la apropiación de las TIC pasa de ser elementos meramente instrumentales a ser fundamentales en un sistema eficiente. Lo que hace que la escuela de respuesta a los retos a los que se enfrenta y adquiera el nuevo papel que ha de asumir, desde un paradigma inclusivo e intercultural (López, 2015).

Por su parte, Cabero (2015), considera a las TAC como instrumentos facilitadores del aprendizaje que se usan en la difusión de conocimiento y saberes; estas tecnologías deben ser vistas como herramientas para la realización de actividades para el aprendizaje y su uso 
más formativo, tanto para docentes como para los educandos, con el objetivo de aprender de manera más significativa.

Con el uso de las TAC, se puede utilizar en los procesos de enseñanza y aprendizaje un abanico de medios y recursos en diferentes formatos que pueden responder a los diferentes canales de percepción de los estudiantes y a las inteligencias múltiples que estos tengan más desarrolladas. Por tanto, estas TAC son ideales para mejorar los aprendizajes en los estudiantes, haciéndolos significativos, pertinentes y adecuados a los diferentes contextos a los que pertenezcan los estudiantes. Entre los medios digitales que se emplean con el uso de las TAC, se encuentran: la Webquest, Escuelas 2.0, hipermedios tales como: edublogs, ebook, podtcast, sitios web, audios, películas y videos.

Según (Szczurek, 1984), los sistemas de enseñanza y aprendizaje tienen seis subsistemas que se interrelacionan entre sí. Estos son: elementos directrices, docente, estudiante, evaluación, estrategias, los medios y otros recursos. Estos últimos constituyen múltiples vías para el logro de los objetivos, son fuente de estímulos sensoriales o kinestésicos que motivan el aprendizaje. Además, permiten a los estudiantes, como centros del aprendizaje, gestionar y ser responsables de su propio aprendizaje.

Dado lo anterior es conveniente incluir en las planificaciones y ejecuciones de las clases, medios que tomen en cuenta todos los tipos de inteligencias y estimulen los diferentes canales de percepción: ambientes con variedad de medios multicoloridos, movimiento, música de fondo. El docente, mediador social por excelencia, debe estar en movimiento en su salón de clases, hablando y mirando directamente a la cara del que aprende, utilizando esquemas, diagramas, hipermedias que en sí ya tienen involucrado imágenes, sonido y movimiento lo que implica que toma en cuenta todos los canales sensoriales del individuo (Guzmán, \& Castro, 2005).

También se debe comprender que todos los adelantos tecnológicos promueven cambios en los modelos de formación, capacitación y adiestramiento de los participantes de cualquier característica biopsicosocial, razón por la cual es imprescindible cambiar los materiales instruccionales. Utilizar medios y recursos adaptando los tradicionales a las nuevas tendencias incluyendo los medios en formato electrónico, propician en el participante actividades en las cuales se realicen trabajos cooperativos y colaborativos en pro de alcanzar las metas propuestas en sus actividades académicas (Castro y Guzmán, 2005 (a, b); De Marco y Guzmán, 2012).

Hay que señalar que según Szczurek (1984), los medios de instrucción, electrónicos o no, son importantes porque: reducen considerablemente el tiempo dedicado al aprendizaje porque objetivan la enseñanza, aprovechan en mayor grado las potencialidades de los órganos sensoriales, se logra una mayor permanencia en la comprensión, transferencia y retención de los conocimientos, se puede transmitir mayor cantidad de información en menos tiempo y se eleva, por lo tanto, la probabilidad de éxito en el aprendizaje, motivan el aprendizaje y activan las funciones intelectuales para la adquisición del conocimiento.

En relación con lo anterior, Marqués (2011) señala que los medios tienen las funciones de: proporcionar información, desarrollar y ejercitar habilidades, motivar, despertar y mantener el interés, evaluar los conocimientos y las habilidades que se tienen, proporcionar simula- 
ciones que ofrecen entornos para la observación, exploración y la experimentación, proporcionar entornos para la expresión y creación, mediadores entre la realidad y los estudiantes.

\section{METODOLOGÍA}

Este artículo forma parte de un conjunto de estudios dirigidos a reconstruir teóricamente la incursión de las TIC en todos los elementos del sistema instruccional de la universidad que llamaremos: "la inserción de las TIC en el la UPEL". Sobre esta temática se han producido ya diversos trabajos, artículos, conferencias y ponencias. En esta oportunidad se desarrollarán aspectos esenciales de los medios y recursos instruccionales por su importancia educativa y primordialmente de aprendizaje, su producción, clasificación y algunos ejemplos.

La metodología empleada radicó en la selección y compilación de información proveniente de documentos y materiales bibliográficos y no bibliográficos que permitieron reflexionar y compilar realidades teóricas y empíricas donde se indaga, interpreta y transcriben hallazgos sobre el estado del arte en relación con los medios instruccionales, un poco de historia, conceptos, clasificación y el diseño de los mismos. Para ello se realiza una bibliografía anotada que generó una matriz donde se plasma el arqueo de la fuente, el análisis y el resumen de la información relevante para ser utilizada en este nuevo documento.

\section{RESULTADOS}

En primer lugar, se tienen las nuevas tendencias relacionadas con las TIC referidos a ámbitos más formativos como son las TAC, por ello se revisaron artículos de autores como Lozano (2011), Montero (2014), Castañeda y Adell (2013), RM (2015), y Cabero (2015), además en relación con la historia y otros aspectos relacionados con los medios instruccionales, se revisaron artículos de autores como: Guzmán (2005, 2008, 2013), Szczurek, (1984), Castro y Guzmán $(2005,2020)$. El análisis de la información proveniente de estos documentos cuyo aporte se consideran como más relevantes para el desarrollo de este artículo son resumidas en los párrafos que se muestran a continuación.

\section{DISCUSIÓN}

\section{Medios, un poco de historia}

Cuando se da una mirada retrospectiva y se ve la información acerca de los medios, se observa que para muchos la línea de separación entre medio instruccional y medio comunicacional es tan delgada que se confunde un término con el otro. La razón es muy sencilla, muchos de ellos nacieron como medio de comunicación de masas y por su potencialidad al darle una finalidad educativa se convirtieron en medio didáctico, algunos ejemplos son: la radio, el cine, la televisión, la prensa, ahora el chat y las redes sociales. Los medios de comunicación son parte de los sentidos de los humanos, que si se asocian al ámbito educativo pueden ser considerados como medios didácticos. 
Mientras Szczurek (1984 s/p citado por Guzmán $(2013,2018)$ señala que "se entiende por medio cualquier persona, objeto u organismo que contenga o proporcione, en sí mismo, información necesaria para facilitar un determinado aprendizaje de conocimientos, actitudes o habilidades". Habiendo dicho esto, se hará un poco de retrospección y una descripción enmarcada en la historia de los medios de instrucción, en ella se puede corroborar que estos han sufrido muchos cambios a lo largo del tiempo, consecuencia de la evolución de la sociedad.

Al meterse en ese túnel del tiempo y recorrer, un poco atrás en la historia, se encontró que en la antigüedad aquellos que se iniciaban en una profesión u oficio se llamaban aprendices, estos firmaban un contrato en el cual el maestro se comprometía a enseñar y el joven se obligaba a aprender. Además, el joven debía obedecer al maestro, acudir al sitio de trabajo todos los días, sin ausentarse y guardar fidelidad al maestro.

Este aprendiz interesado en aprender una tarea debía hacerlo, por imitación, observaba al maestro (carpintero, cocinero, escultor, pintor) que intencionalmente o no, explicaba con objetos concretos de uso diario en el oficio, y totalmente contextualizados, el cómo, el cuándo y para qué usar esos objetos con el fin de aprender el oficio.

Esta práctica de enseñanza incluía que la planificación, los medios a usar las realizaba el maestro pensando en él mismo y la tarea a realizar. El maestro tenía toda la información, decodificaba el mensaje y lo orientaba hacia el desarrollo de la meta específica, su medio primordial era su voz y la experticia en el uso de los materiales requeridos. Hay que acotar que esta información debía ser internalizada y reproducida por el aprendiz de la misma manera como fue enseñada.

Hay autores que consideran que la historia de los medios va a la par del pizarrón, el puntero, las tizas u otro material para escribir, entre otros, ya que han sufrido algunas modificaciones, pero permanecen como los recursos por excelencia utilizados por el docente durante la evolución de los procesos instruccionales, llegan al punto de considerarlos imprescindibles e inseparables del educador y del educando.

Para estos autores la concepción y utilización de los medios variaba de la misma manera que variaban los dispositivos, con el tiempo, se tomaron en cuenta otros criterios como son: las características del participante, el número de alumnos, el contexto, las características del docente, la iluminación, electricidad, una serie de variables que se están tomando en cuenta desde los años 40. En esos años psicólogos y educadores (tecnólogos educativos) pusieron en práctica programas basados en el logro de objetivos precisos y concretos de aprendizaje, que implicaban el desarrollo de destrezas específicas según las tareas a desempeñar, mostraban ¿cómo presentar la información?, ¿cómo organizar a los alumnos?, ¿qué prácticas deben realizar?, ¿cuál era utilización de los recursos audiovisuales, y medición precisa de los resultados de aprendizaje a través de pruebas estandarizadas? (Área, 2009).

Este mismo autor considera que en las décadas de los 50 y 60 la Tecnología Educativa cuyo objeto de estudio es la introducción de medios y recursos de comunicación, para incrementar la eficacia de los procesos de enseñanza y aprendizaje como campo de estudio dentro de 
la Educación surge en el contexto americano de los años cincuenta debido a tres factores: a) La difusión e impacto social de los mass media: ${ }^{3}$ radio, cine, tv y prensa. b) El desarrollo de los estudios y conocimientos en torno al aprendizaje del ser humano bajo los parámetros de la psicología conductista. c) Los métodos y procesos de producción industrial (Área, 2009, p. 16).

Los medios instruccionales han cambiado de acuerdo a la teoría de aprendizaje imperante, así se puede reseñar que en los años $50^{\prime}$ se consideraban los medios como ayudas para presentar los estímulos para ello era estrictamente necesario presentar la información en pequeños paquetes que debían ser seguidos de la misma manera. Allí se tiene el auge de la instrucción programada, lineal, o ramificada, que siempre implicaba un reforzamiento, o un castigo según sea la respuesta del estudiante. Los dispositivos para enseñanza audiovisual, enseñanza programada, los tutoriales son los mejores ejemplos de los mismos.

En los años 60 y 70 se desarrollaron modelos más sistemáticos para el proceso de producción, diseño y uso de medios como la radio y la televisión para potenciar los procesos de enseñanza y aprendizaje tanto presenciales como a distancia, el sistema educativo ha sabido integrar los valores formativos de estos medios, han hecho radio y televisión aprovechando estos medios para hacer una Educación más activa, participativa, democrática, crítica y solidaria.

En estas décadas se comienza a experimentar con otros productos de la Tecnología como son el retroproyector o el cinematógrafo, estos últimos medios solo contribuyeron a presentar contenidos presenciales de manera más eficiente. Cabe acotar que los medios debían responder a un criterio de selección y a las características propias del medio para hacerlos atractivos a la audiencia. Además, deben ser elaborados por profesionales expertos en las temáticas a estudiar y el lenguaje a usar.

Los adelantos tecnológicos de los años 80 y 90, entre ellos las Tecnologías de Información y Comunicación (TIC), permitieron a los diseñadores de materiales instruccionales desplazarse más hacia el constructivismo, tomando en cuenta a la audiencia para el desarrollo de los mismos. Una de las herramientas más útiles que surge es el hipertexto y la hipermedia porque permiten realizar diseños ramificados en lugar de lineales como tradicionalmente se han hecho.

Con la incorporación de las TIC entre las estrategias y medios instruccionales se favorecen los procesos de enseñanza y de aprendizaje, además se observan nuevas formas de comunicación verbal y no verbal de los actores del sistema. Se ejecutan otras maneras de presencia y de interacción docente-alumnos, alumnos-alumnos, alumnos-materiales electrónicos, contenidos en formato CDROM, software, sitios Web, las nuevas formas de encontrar, acceder y discriminar la información.

Los Medios Instruccionales influyen y condicionan la organización de los procesos de enseñanza y aprendizaje, la relación profesor-alumno, la adecuación de espacios, la duración de las actividades, el desempeño por parte del profesor de determinadas funciones didácticas 
y extra-didácticas. No obstante, estos medios también están condicionados por el marco curricular donde se insertan: espacios y recursos disponibles, características de los estudiantes, entre otras cosas (Cabero, 1991; Szczurek, 1978).

Desde el enfoque curricular contextualizado, los medios además de ser los que tienen y transmiten la información son sistemas simbólicos, que atienden a todos los elementos del contexto, ya que pueden delinear nuevas relaciones entre profesores, alumnos con su entorno.

\section{Medio instruccional, otros conceptos}

En Educación no se concibe que el docente prepare estrategias que no incluyan los medios y otros recursos que según Szczurek (1989) son el "con qué" de los sistemas de enseñanza y aprendizaje. Según Marqués (1999) se conceptualiza medios y recursos como: cualquier dispositivo o equipo que se usa normalmente para transmitir información entre las personas (...). Un medio educativo es un dispositivo de este tipo que se utiliza con fines educativos" (perspectiva instrumental y finalidad comunicativa o informativa) (Rossi y Bidlle 1970 p18)," son formas o vehículos replicables a través de los que se da forma, se almacena y se entrega la instrucción al estudiante". (Schramm, 1977). "es cualquier persona, material o acontecimiento que establece las condiciones para que el alumno adquiera conocimientos, capacidades y actitudes".

Fernández y Hernández (1995, p. 109) citan a McLuhan y señalan que los medios inciden en los mensajes que transmiten, en tal forma que integró esta idea en su famosa frase "el medio es el mensaje", los mediadores tanto instrumentales como sociales se basan en la comunicación verbal y no verbal, que tiene factores como son: fuente, mensaje, canal y receptor.

Ahora bien, según Guzmán $(2013,2018)$ hay medios didácticos que requieren del uso de soportes computarizados tales como:

1. Edu-blogs, blogs son herramientas productivas y usadas en varios ámbitos, semejantes a cuadernos de bitácora, flexibles de interacción que permite otras formas de producir y publicar contenidos sin la necesidad de ser experto, generalmente asociado a un grupo de Facebook o mensajería de aula virtual para aumentar su interactividad.

2. Sitios web: conjunto de páginas web, imágenes, vídeos u otros archivos digitales comunes a un dominio de Internet o subdominio en la Web, mientras que las páginas web son documentos electrónicos diseñados para el World Wide Web que contiene algún tipo de información.

3. E-book: El libro electrónico, libro digital, ecolibro, o libro-es un texto digitalizado que tiene como soporte un archivo electrónico en vez de papel.

4. Podcast consiste en la distribución de archivos multimedia o hipermedia (audio o video que suelen ser de corta o larga duración, que pueden incluir texto como subtítulos y notas, mediante un sistema de redifusión (RSS) que permite suscribirse y usar un programa que lo descarga para que el usuario lo escuche. 
5. Los contenidos en formato CD ROM. DVD o memorias USB, pueden ser usados en literatura, juegos, música, poesía, cuentos, contenidos educativos y puede contener todos ellos al desarrollar un tema en particular, es porque la intención del CD a desarrollar o evaluar los clasifica en recreativos, divulgativos, informativos siempre tomando en cuenta que en él interactúan multimedios, y en algunos casos hipertextos. (Pasando de multimedio a hipermedia). En ellos se puede almacenar gran cantidad de información en diferentes formatos siempre con la ayuda de un soporte tecnológico para su ejecución.

En este mismo orden de ideas De Marco y Guzmán (2005, 2012) citando a Amorós (2003) señalan que cuando se habla de las aplicaciones informáticas hipermedia para la enseñanza pueden referirse a multimedias o de la combinación de lenguajes o códigos textuales, sonoros, icónicos, estáticos o en movimiento, que contienen información interconectada, a modo de pequeños paquetes interactivos que le permiten al estudiante navegar de un modo no lineal, libre, con estrategias cognoscitivas y constructivistas que le permitan obtener un mayor y mejor aprendizaje de manera significativa.

La utilización de medios electrónicos permite la difusión efectiva de la información relacionada con el tema, pero también su uso permite la conservación del ambiente un ejemplo de ello lo señalan González, \& Guzmán (2010, p. 144) quienes consideran que es necesario "promover una Educación del consumo adecuado del uso del papel, ya que para producir grandes cantidades de papel se desforestan bosques naturales o plantaciones forestales". Por su parte Moreira (1999) considera que mediante los materiales didácticos es posible generar y organizar los procesos necesarios para la innovación e integración de las TIC, por sus características hipertextualidad, multimedia, interactividad.

\section{Los medios instruccionales y su clasificación}

Existen una gama de medios que van desde los elaborados por el docente hasta sofisticados programas de computación. Así como también hay diversas maneras de clasificar los medios instruccionales como son: el canal sensorial, el control del estudiante sobre el medio, la utilidad del medio para pequeños o grandes grupos de estudiantes.

La clasificación de Szczurek (1984), no incluye los multimedia e hipermedia, debido a que fue realizada antes de que estos medios estuvieran desarrollados, por tanto, son añadidos por los autores de este artículo. Se debe resaltar que Szczurek (1996) con su trabajo de ascenso a titular incluye el uso de hipertextos. Distintos autores han realizado clasificaciones de materiales didácticos siguiendo diversos criterios, por lo que no hay un modelo estándar ni único, pero los autores consideran que la presentada en el cuadro 1 es la más completa y aceptada en el mundo educativo en Venezuela.

Esta clasificación de medios está basada en los materiales para el Centro Nacional para el Mejoramiento de la Enseñanza de la Ciencia (CENAMEC, 1984), En él se muestran las categorías y subcategorías para la clasificación de medios instruccionales, el concepto del canal de percepción y algunos ejemplos de medios. Cabe señalar que los multimedia e hipermedia pueden incluirse dentro de los multisensoriales, ya que se involucran todos o algunos de los sentidos del participante. 
Tabla 1

Tipos de Medios Instruccionales Szczurek (1984), agregado de Guzmán (2013)

\section{CATEGORÍA CONCEPTO \\ Visual: Estimulan \\ esencialmente el sentido de la vista. Un medio visual utiliza un lenguaje icónico}

Auditivo: Estimulan esencialmente el sentido de la audición

\section{Audiovisual: Todos} aquellos que se perciben simultáneamente tanto a través del sentido de la vista como a través del oído
De imagen fija

De imagen con movimiento

\section{ALGUNOS EJEMPLOS DE MEDIOS}

Textos, rotafolio, dibujos, módulos autoinstruccionales o no, revistas, periódicos, transparencias, diapositivas, láminas, pizarrón, libros, filminas, fotografías, mapas, papelógrafos, fichas de trabajo, carteles, murales, magnetogramas

Película muda, videocinta muda

Audiocinta, disco, programa de radio, casete, disco compacto, DVD audio, mp3. Audio digital, audiolibro, radionovelas, audio-clips

En general, cualquier combinación entre visuales de imagen fija y auditivos

Sonoviso, presentaciones didácticas fijas o en serie, un reproductor de audio y ocasionalmente algún juego de luces (como en los espectáculos al aire libre en ruinas o edificios históricos)

movimiento

Películas, videocintas, TV, CD ROM,

\begin{tabular}{c|l} 
De imagen con & $\begin{array}{l}\text { Peliculas, videocintas, TV, } \\
\text { movimiento }\end{array}$ \\
presentaciones animadas
\end{tabular}

Personas Docente

Multisensorial: Son aquellos que estimulan todos los sentidos incluyendo visual y auditivo acercándose un poco más a la realidad

Multimedia: se utiliza para referirse a cualquier objeto o sistema que utiliza múltiples medios de expresión físicos o digitales para presentar o comunicar información

Hipermedias: hipermedia toma su nombre de la suma de hipertexto y multimedia, una red hipertextual en la que se incluye texto, medios: imágenes, audio, vídeo, entre otros. (Multimedia)
World Wide Web, Sitios Web, Redes sociales, Blog, e-book, Contenidos en Formato CD, Wikis, Wikipedia 
Es de resaltar que el término multimedia sigue siendo confuso pues todavía no ha sido bien definido y sus límites resultan difusos. Si a finales de la década de los 70, multimedia era la integración de voz, texto, datos y gráficos, en los 90 a estos elementos se suman los gráficos interactivos, las imágenes en movimiento, las secuencias de audio y vídeo, las imágenes en tres dimensiones, la composición de documentos digitales y la realidad virtual, es la combinación o utilización de dos o más medios de forma concurrente (Lamarca, 2011).

Es de acotar que los multimedios no están restringida a la informática: unas fotografías sincronizadas con un audio es una obra multimedial, sin embargo, poco a poco, el término multimedia se ha generalizado para referirse a la informática y al mundo digital. En cuanto a los hipermedias son definidos como el conjunto de métodos para escribir, diseñar, la forma de presentar la información, sean mapas mentales o conceptuales, texto, videos, sonidos, imágenes y demás formas de información, por medio de unidades discretas o nodos que se unen por medio de enlaces (o hipervínculos) que permiten una acción interactiva con los usuarios (Lamarca, 2011).

El mismo autor considera que otro de los cambios sustanciales a los que nos enfrenta la hipertextualidad, es la unión de texto, imagen, historietas (iconos, diapositivas, fotografías, cuadros), sonido (música, sonidos de todo tipo, programas de radio) y otros medios audiovisuales y multimediales, lo que ofrece un particular dinamismo al hipertexto, convirtiéndolo en hipermedia y haciendo que el modo literal se convierta en visual y auditivo y por ende multisensorial.

Todo docente cuando va a mediar un conocimiento debe seleccionar el o los medios más adecuados para que el mensaje llegue con claridad y se dé el aprendizaje, ¿con cuál enfoque? el que sea más adecuado al tema a trabajar, como dicen Ertmer \& Newby (1993) hay que ser eclécticos en cuanto a las teorías conductistas, cognoscitivista, constructivistas, o conectivistas y tomar de cada uno lo que sea pertinente para el logro del aprendizaje. Los enfoques producen competencias diferentes, pero ninguno niega que el aprendizaje tenga influencias de los conocimientos previos y el proceso va cambiando constantemente, tanto en su naturaleza como en su diversidad. El docente debe tener una serie de criterios para realizar esta tarea. A continuación, se mostrarán algunos de ellos.

\section{La selección de medios}

En todos los procesos de enseñanza y de aprendizaje es necesario el docente, facilitador o mediador social, quien selecciona los medios adecuados en función de una serie de criterios para la toma de decisiones como son: el contexto, el contenido las características de los grupos, sus propias características como docente y de la audiencia para quienes están destinados por ello debe tener experticia en el tipo, manejo, uso de los contenidos conocimiento del contexto y de los medios lo que le permitirá una selección más adecuada y efectiva.

Este docente debe escoger y clasificar entre la cantidad de medios instruccionales, clasificación ésta que luego sirve de base para su selección. Si los medios de instrucción sean electrónicos o no, son bien seleccionados, producidos, utilizados y evaluados, estarán totalmente interrelacionados con los otros elementos del sistema mediaran el aprendizaje con mayor efectividad y eficiencia, ahorrando esfuerzos y tiempo y con mayor satisfacción por parte de los actores del sistema (docente, estudiantes padres o representantes).

La selección y uso de los materiales didácticos se hace atendiendo a una visión sistémica, por lo que deben estar en correspondencia con las competencias, los objetivos y propósitos, los contenidos a impartir, los aprendizajes esperados, las estrategias y las actividades programadas. 
No hay una receta única para seleccionar un medio, pero hay consenso en que debe estar contextualizado y tomar en cuenta los factores que determinan su efectividad y eficiencia, lo que repercute en el logro de las competencias planificadas.

Al respecto Dorrego (1994) coincide con estos factores y señala que la selección de los medios depende de (a) Los objetivos, contenidos o competencias a lograr, según la categoría donde se ubique el aprendizaje (información verbal, habilidades intelectuales, destrezas cognoscitivas, habilidades motoras, actitudes); y el tipo de retroalimentación requerido según las clases de resultados esperados. (b) Las estrategias instruccionales a ser utilizadas y el enfoque seleccionado para realizarlas. (c) Los atributos inherentes a los medios, es decir, sus capacidades para transmitir los estímulos requeridos para el logro de los aprendizajes; y las formas de presentación. (d) Las características del contenido a ser transmitido, mediado o facilitado (grado de abstracción, complejidad, estructuración). (e) Las características de los alumnos, diferencias individuales, experiencia previa con los medios. (f) Las características de los docentes en cuanto a sus habilidades para el diseño, elaboración y uso de materiales instruccionales, y su actitud ante los mismos. Y, (g) la factibilidad de producción y uso. El docente también debe tomar en cuenta si se tiene o no el medio, si está o no disponible, o si debe diseñar o rediseñar el medio.

\section{Diseño y producción de medios}

Se debe comenzar por señalar que antes de seleccionar y/o producir los medios, los docentes deben: tener nociones de lo que es un medio, sus tipos y su uso. Investigar lo que hay realizado en cuanto al medio y al tema a desarrollar. Determinar la preparación, los requisitos técnicos y didácticos. hacer equipos interdisciplinarios de ser necesario. Manejar con propiedad el contenido y la teoría de aprendizaje que se preste mejor al conocimiento a mediar.

Lo que no debe hacer un docente es diseñar algo sin tener las herramientas, o sin tener un contenido completo. Tampoco debe hacer medios con textos tan extensos que aburran, cansen y en lugar de servir de motivación se obtenga el resultado contrario.

Los docentes en su mayoría de diferentes áreas deben desarrollar prototipos de hipermedias con los programas que decidan y usando el modelo de diseño de medios que mejor se adapte a sus necesidades, el tema, para el contexto y la audiencia para el cual ha sido diseñado. Para ello se plantean las siguientes fases: a) selección del medio a realizar, b) recopilación, manipulación y ubicación en carpetas digitales de los materiales a usar, c) diseño y elaboración del primer prototipo del hipermedias y d) validación del medio. A continuación, se explicarán cada una de esas fases.

En la fase de selección, el participante del curso debe tomar en cuenta:

1. Las características del contexto y la audiencia para quienes está dirigido. El contenido a desarrollar debe: Tener información precisa y exacta, claridad en los términos a usar. Poseer un dialogo de acuerdo a la audiencia y debe estar mostrado de manera creativa y ser propiciador del pensamiento crítico y creativo.

2. El tipo de medio electrónico que elaborará es decir el que contiene la información y la fuente de estímulos para el desarrollo de la audiencia.

3. El modelo de guión de contenido que usará. 
4. La teoría de aprendizaje y la secuencia del aprendizaje que define las habilidades y destrezas a alcanzar al finalizar la instrucción. (puede ser jerárquico, procedimental o combinado).

5. El modelo de diseño pedagógico que debe usar (radial, lineal secuencial, matricial, jerárquica o una combinación de estos) está íntimamente relacionado con el tipo de contenido, el enfoque utilizado para enseñarlo, a la audiencia para quienes está destinado, el tipo de interrelaciones que se darán en el contenido y la forma de acceso que el estudiante tendrá a la información. En la figura 1, que se muestra a continuación, se pueden observar los modelos antes mencionados.

\section{Estructura Matricial}

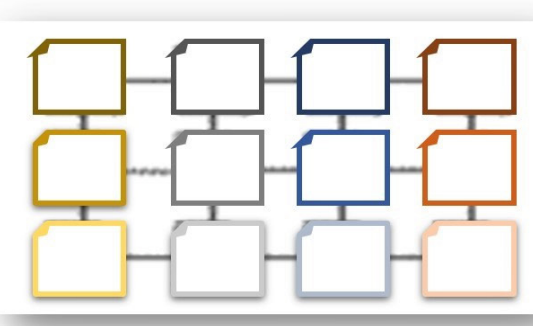

Estructura Jerárquica

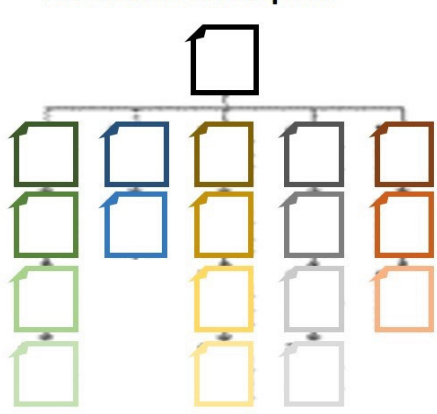

Estructura Secuencial
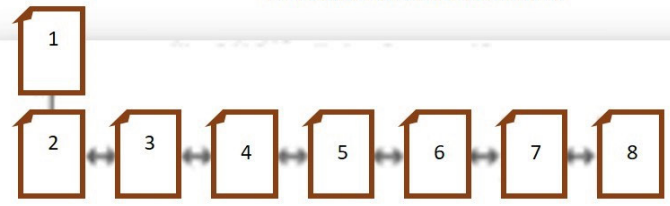

Estructura En red

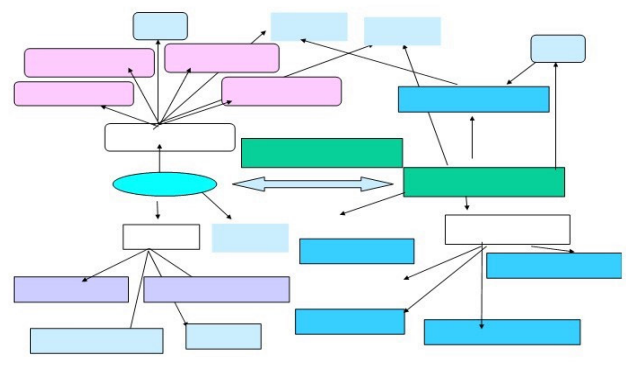

Figura 1. Modelos de estructuras utilizadas para realizar el diseño pedagógico

En el desarrollo de los hipermedias se requiere que la estructura a utilizar en el diseño sea la estructura en red, pero con la jerarquía que implica el conocimiento de acuerdo a la audiencia seleccionada. Se sugieren los siguientes pasos:

En la fase recopilación, manipulación y ubicación, es bueno tener un portafolio de carpetas digitales de los materiales, se debe hacer estas carpetas previamente identificadas para el almacenaje y posterior uso de los materiales a utilizar en el desarrollo del medio, en ella se almacenan: Fotografías, Videos, audios, Sonidos, Archivos de texto para enlazar, Imágenes digitales: creación, captura y tratamiento, con el uso del escáner, la cámara y el vídeo digital, Contenido bajado de internet, historietas, infografías. Buscar, seleccionar la información digitalizada o transcribirla de ser necesario, Archivos no digitalizados por lo que se hace necesario escanearlos, Recortes de prensa, listado y extractos de prensa, enlaces a grupos de Facebook, a blogs, bibliotecas digitales, sitios web para más información. 
Para la realización de la etapa de diseño y elaboración del primer prototipo del hipermedio se requiere:

1. Realizar el guión técnico, que debe ser sencillo, claro, adaptable e interactivo. En él se muestra las especificaciones visuales, la calidad de enlaces, la navegación, el nivel de interactividad y la forma de realimentación al proceso, entre otros.

2. El diseño de un prototipo. Hay que acotar que el diseñador instruccional no tiene por qué encargarse de la parte técnica, es por ello que se requiere de un equipo multidisciplinario. El diseñador debe decidir si se requiere ayuda técnica o si lo elaborará el mismo docente.

3. Dependiendo del medio que se haya seleccionado para su producción existen una serie de plantillas: blogs, ${ }^{4}$ ebook,${ }^{5}$ contenidos en formato $\mathrm{CD}-\mathrm{ROM}^{6}$ que tienen como base varios programas sobre plataformas sencillas o no, cursos en línea en moodle u otro formato, sitos webs gratuitos $^{7} \mathrm{y}$ otros que requieren conocimientos técnicos como los videos educativos.

4. Si se requiere la ayuda de los técnicos, se hace necesario conformar equipo de trabajo para su desarrollo. Hay que acotar que el técnico no es quien tiene la voz cantante, el líder del equipo es el diseñador del medio, el técnico informático es quien conoce de la técnica, la estructura informatizada, no de la información requerida para el estudiante.

5. Revisión de la portada del mismo, debe ser atractiva y motivante.

6. Revisión de los enlaces, tamaño de letra, colores de letras y fondo, tipos y tamaño de las imágenes, sonido, otros programas a usar (el tamaño y tipo de letra, así como las imágenes deben estar de acuerdo a la edad de la audiencia para la cual está dirigida, (debe respetar las diferencias individuales).

7. Revisión de interactividad, lenguaje del autor, calidad y cantidad de información por pantallas o páginas.

8. Fijación de los conocimientos previos que debe tener el usuario y requerimientos técnicos necesarios para su uso efectivo.

La fase de validación del medio está contemplada para todo el proceso de diseño del prototipo, en ella se muestran las variables a evaluar, el procedimiento empleado, los instrumentos utilizados y quienes fueron los responsables de la ejecución. Esta evaluación se realiza en tres momentos: cuando se tiene el producto inicial, el intermedio y el prototipo (listo para revisión por parte de una muestra de la audiencia), en todo caso se emiten juicios de valor en relación con la adecuación de guiones, al contenido, a la audiencia, validez de fachada y contenido entre otros. Por lo que incluye evaluación por: expertos en el tema tratado; usuarios facilitadores (docentes); usuarios participantes; expertos en lenguaje verbal (oral y escrito); expertos en lenguaje no verbal (iconográfico, infográfico), expertos en informática, en TIC y TAC.

4. http://www.hazblog.com; www.blogger.com; blog.webnode.es

5. http://www.myebook.com

6. http://www.prezi.com; PowerPoint

7. www. paginawebgratis.es; www.webnode.com.ve 


\section{CONCLUSIONES}

A manera de conclusión se puede señalar que los medios instruccionales son el con qué del sistema de enseñanza y aprendizaje, que se deben seleccionar, diseñar o rediseñar y desarrollar por todos los profesionales de la Educación. Los medios y recursos basados o no en las TIC se deben considerar como aliados que poseen, median y transmiten los conocimientos, independientemente del nivel o la modalidad de estudio que se use para la interacción entre los actores del sistema.

En la actualidad no hay estrategia innovadora que no contemple un abanico de opciones que tenga como ayuda a los medios y recursos instruccionales. Por lo tanto, es importante que todo docente maneje los medios con propiedad, puesto que no se sabe cuáles son las condiciones del contexto donde corresponde impartir la instrucción y es allí donde su creatividad y experticia deben emerger.

\section{REFERENCIAS}

Área, M. (2009). Introducción a la Tecnología Educativa. http://issuu.com/manarea/docs/ tecnologiaeducativa

Cabero, J. (1991). Actitudes Hacia los Ordenadores y la Informática. Medios y recursos didácticos. Publicaciones de la Universidad de Málaga.

Cabero, J. (2015). Reflexiones educativas sobre las tecnologías de la información y la comunicación (TIC). Tecnología, Ciencia y Educación, (1), 19-27. https://idus.us.es/xmlui/bitstream/ handle/11441/32285/Reflexiones_educativas_sobre_las_Tecnolo.pdf?sequence $=1$

Cabero, J. (2017). Educación Primaria en Canarias, y otras variedades. http:// educaprimariacanarias.blogspot.mx/2015/03/tic-tac-y-tep-nuevas-miradas-sobre-las.html

Castañeda, L. y Adell, J. (2013). La anatomía de los PLEs. En L. Castañeda y J. Adell (Eds.), Entornos personales de aprendizaje: Claves para el ecosistema educativo en red (pp. 11-28). Marfil. https://digitum.um.es/digitum/bitstream/10201/30427/1/ CastanedayAdelllibroPLE.pdf

Castro, S., \& Guzmán, B. (2005). Los estilos de aprendizaje en la enseñanza y el aprendizaje: una propuesta para su implementación. Revista de investigación, (58), 4. https://dialnet.unirioja. es/descarga/articulo/2051098.pdf

Castro, S., Guzmán, B., \& Casado, D. (2007). Las TIC en los procesos de enseñanza y aprendizaje. Laurus, 13(23), 213-234. https://www.redalyc.org/pdf/761/76102311.pdf

De Marco, A. P. R., \& Guzmán, B. (2012). Un ambiente Web para la asignatura simulaciones y juegos instruccionales de la Universidad Pedagógica Experimental Libertador. Revista de Investigación, 36(75). http://revencyt.ula.ve/storage/repo/ArchivoDocumento/ipcupel/n75/ art06.pdf

De Marco, A. y Guzmán, B. (2005). Evaluación del curso simulaciones y juegos instruccionales del departamento de tecnología educativa en el Instituto Pedagógico de Caracas. (Inédito). UPEL-IPC. 
Dorrego, E. (1994). Modelo para la producción y evaluación formativa de medios instruccionales, aplicado al video y al software. Revista de Tecnología Educativa, 12(3), 313-327. http:// www.c5.cl/ieinvestiga/actas/ribie94/II_72_84.html

Ertmer, P., \& Newby, T. (1993). Conductismo, cognitivismo y constructivismo: una comparación de los aspectos críticos desde la perspectiva del diseño de instrucción. Performance improvement quarterly, 6(4), 50-72.

Fernández, C y Hernández, R. (1995). Marshall Mcluhan: el explorador solitario. Grijalbo. Guzmán, B. (2005). Actitudes de los docentes ante las Tecnologías de Información y Comunicación. (Doctorado no publicada). Universidad Pedagógica Experimental Libertador

González, H. G., \& Guzmán, B. (2010). Principios Didácticos para la elaboración de un E-Book en salud sexual y reproductiva. Revista de Investigación, 71(34), 141-167.

Guzmán, B. (2008). Los docentes de la universidad pedagógica experimental libertador-instituto pedagógico de Caracas ante las tecnologías de información y comunicación. Investigación y postgrado, 23(1), 37-72. https://dialnet.unirioja.es/descarga/articulo/2754753.pdf

Guzmán, B. (2013). Evaluación del Curso Tecnología de Información y Comunicación y Educación Ambiental a Través de sus Productos. (Trabajo de Ascenso para optar a la categoría de profesor Titular). Universidad Pedagógica Experimental Libertador, Instituto Pedagógico de Caracas.

Guzmán, B. (2018). TIC y Medios. [conferencia] 27. Encuentro Nacional de Profesores de Francés. Asociación Venezolana de Profesores de Francés. Venezuela.

Guzmán, B., \& Castro, S. (2005). Las inteligencias múltiples en el aula de clases. Revista de investigación, (58), 177-202. https://www.redalyc.org/pdf/3761/376140372009.pdf

Lamarca, M. (2011). Hipertexto, el nuevo concepto de documento en la cultura de la imagen. (Doctorado) Universidad Complutense de Madrid. http://www.hipertexto.info

López, M. R. (1 de noviembre de 2015). TIC, TAC, TEP atom. http://tictactepmarilin.blogspot. com/2015/11/tic-tac-tep-tecnologias-la-informacion_1.html

Lozano, R. (12 de enero de 2011). De las TIC a las TAC: tecnologías del aprendizaje y del conocimiento (A. thinkepi, Ed.). http://www.thinkepi.net/las-tictac-de-las-tecnologias-de-lainformacion-y-comunicacion-a-las-tecnologias-delaprendizaje-y-del-conocimiento

Marqués, P. (1999). La Tecnología Educativa: Conceptualización, Líneas De Investigación. http:// peremarques.pangea.org/tec.htm

Marqués, P. (2011). Los medios didácticos y los recursos educativos. http://www.peremarques.net/ medios $2 . h t m$

Montero, O. (23 abril de 2014). TIC, TAC, TEP. Tecnologías... para la vida - Servicios y soluciones IT https://www.conasa.es/blog/tic-tac-tep-tecnologias-para-la-vida

Moreira, M. A. (1999). El diseño y desarrollo de materiales didácticos electrónicos. Un proyecto para la educación de adultos en canarias. In EDUTEC: nuevas tecnologías en la formación flexible ya distancia (pp. 1-11). http://www.quadernsdigitals.net/datos/hemeroteca/r_42/ nr_477/a_6369/6369.pdf 
RM, I. (2015). TIC, TAC y TEP. Nuevas miradas sobre las TIC aplicadas en la educación. Julio Cabero Almenara.(Ed) http://educaprimariacanarias.blogspot.mx/2015/03/tic-tac-y-tepnuevas-miradas-sobre-las.html

Szczurek, M. (1978). Tecnología educativa y tecnología instruccional. Revista de Tecnología Educativa 4(3), 257-267.

Szczurek, M. (1984). Los medios de Instrucción (Folleto). Proyecto REC-CN-MAT-EB CENAMEC.

Szczurek, M. (1989). La estrategia instruccional. Revista Investigación y Postgrado, 4(2), 7-26. 